\title{
MATCH development during the EURANOS project
}

\author{
L. ROBERTSON ${ }^{1}$
}

\begin{abstract}
The Multi-scale Atmospheric Transport and Chemistry Model (MATCH) is used in the RODOS (Real-time On-line decision Support) system since more than 10 years for the long range atmospheric transport and dispersion calculations. With the start of the EURANOS project, several functionalities of the model at that time should be further enhanced. This included the better use of the meteorological information available in the numerical forecast data and the coupling to the source term data base of the RODOS system.
\end{abstract}

\section{The MATCH model and its improvements within the EURANOS project}

The regional and long-range transport model in the RODOS system is the MATCH model, Multi-scale transport and Chemistry Model (Robertson et al., 1999). MATCH is a multi purpose model for applications ranging from emergency simulations. of hazardous species to air quality forecasts, hindcasts and climate scenario projections. The MATCH model is facilitated with a set of modules for various reactions schemes and modules for turbulent and dry and wet deposition processes. The model has been evaluated in several inter comparison activities where the MATCH model appears in the top list of good models (e.g. Carmichael et al, 2001; van Loon et al., 2007). The implementation into the RODOS system implies a modularisation demanded by the general RODOS design.

The MATCH model is a so called off-line model that means that weather data are fed into the model on a regular basis. Driving weather data are required from numerical weather prediction models available on so called model levels in order to fully describe the atmospheric motion and turbulence structures. Unfortunately course resolution in the vertical - like weather data on pressure levels - will not work in the MATCH model for several reasons and the results would anyhow be too crude to make sense for emergency assessments.

\footnotetext{
1 SMHI, Norrköping, Sweden.
} 


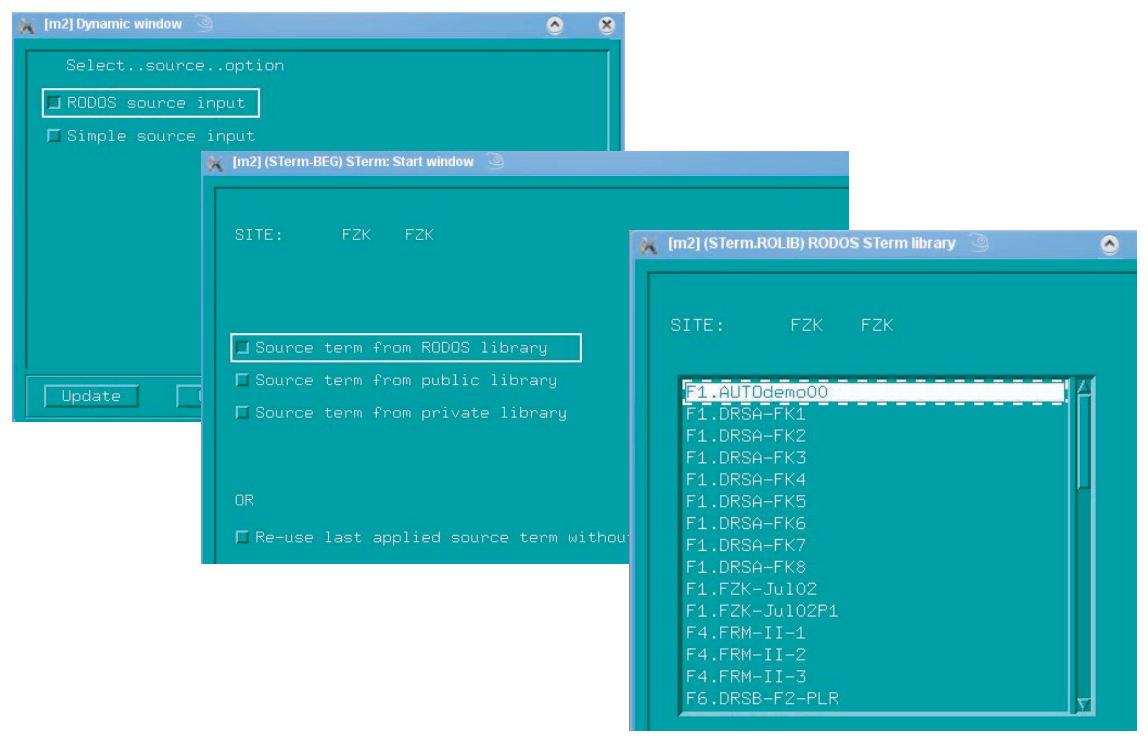

Figure 1 - Source term input with coupling to RODOS source term library.

The model design is made flexible with regard to input weather data in terms of projections and resolutions, but is limited to the use of GRIB1/GRIB2 as the input format. The model normally operates on the same projection and resolution as incoming weather data (both in the horizontal and vertical) but output to the RODOS GIS system is always provided on a lat-long grid whatever input projection used.

MATCH is a semi Eulerian-Lagrangian model with a Lagrangian parcel transport model describing the first phase of the release where the parcels are successively merged into the Eulerian grid and then described by the Eulerian transport model on the long range. The Lagrangian parcel model also plays an important role for seamlessly transfer local scale model outputs given as a train of puffs into the MATCH model. Radioactive decay is accounted for each specific nuclide but there are no nuclide-chain reaction scheme implemented.

Some of the characteristics of the MATCH model implementation if RODOS:

- MATCH implementation with the following source options:

O RODOS source term database;

$O$ user defined source definition;

O model chain where puff data from the near range dispersion models ATSTEP, RIMPUFF or DIPCOT defines the source (see Päsler-Sauer, 2010). 


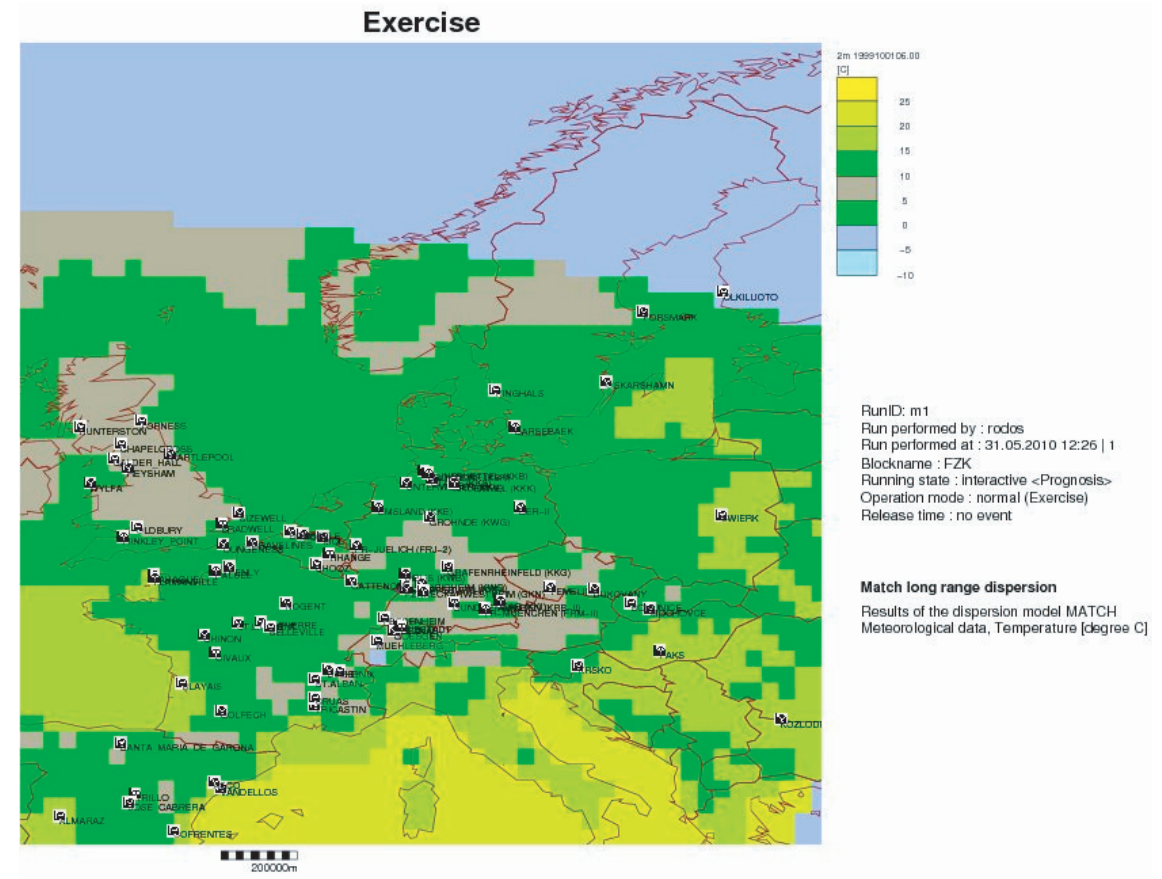

Figure 2 - Temperature distribution over the calculation domain.

- Post process module to prepare output to the countermeasure subsystem.

- Review module for the RODOS GIS as MATCH results are not stored in the RODOS database.

Some of the major improvements over the EURANOS project were full connection to the RODOS source term database and improved GUI and the improved usability. Adaptations have been made to account for enhanced weather data information like the turbulent kinetic energy for deriving the turbulent structure of the atmospheric boundary layer and adaptations to other types of land use data.

The adaptations needed for upcoming weather data are unfortunately a never ending story. We use the WMO standard format for binary field data, the GRIB format (GRIB1/GRIB2), that is the common format for which most numerical weather prediction data are provided. The GRIB1 format allows however for local definitions that prompts for adaptations when used in a system like RODOS. There are unfortunately no easy method to check for local definitions and adaptations further on are most likely to be needed. A hope may be the GRIB2 format that to 
a large extent make local definitions unnecessary. The MATCH implementation do of course account for the GRIB2 format.

Future sources of weather data will most likely be on finer resolutions that may need some adaptation in terms of model extent, horizontally and vertically, in an ongoing process to make the MATCH implementation in RODOS up to date.

\section{Conclusions}

The improvements of the long range atmospheric dispersion model of the RODOS system MATCH can be summarised as a better coupling to the internal RODOS source term data base and the adaptation of the model to the ongoing modifications of the numerical weather data bases provided by the national weather services. This assures that MATCH remains a state of the art tool of the RODOS system.

\section{REFERENCES}

Carmichael G.R., Hayami H., Calori G., Uno I., Cho S.Y., Engardt M., Kim S.-B., Ichikawa Y., Ikeda Y., Ueda H., Amann M. (2001) Model intercomparison study of long range transport and sulfur deposition in East Asia (MICS-Asia), Water Air and Soil Pollut. 130, 51-62.

Päsler-Sauer J., Comparison and Validation Exercises of the Three Atmospheric Dispersion Models in RODOS, Radioprotection 45, S89-S96.

Robertson L., Langner J., Engardt M. (1999) An Eulerian limited-area atmospheric transport model, J. Appl. Met. 38, 190-210.

van Loon M., Vautard R., Schaap M., Bergström R., Bessagnet B., Brandt J., Builtjes P.J.H., Christensen J.H., Cuvelier K., Graf A., Jonson J.E., Krol M., Langner J., Roberts P., Rouil L., Stern R., Tarrasón L., Thunis P., Vignati E., White L., Wind P. (2007) Evaluation of long-term ozone simulations from seven regional air quality models and their ensemble average, Atmos. Envi. 41, 2083-2097. 